\title{
Interleukin-12 Induction of Th1 Cytokines Is Important for Viral Clearance in Chronic Hepatitis B
}

\author{
Siegbert Rossol, ${ }^{\star \S}$ George Marinos, ${ }^{\star}$ Patrizia Carucci, ${ }^{*}$ Manfred V. Singer, ${ }^{\S}$ Roger Williams, ${ }^{\star \ddagger}$ and Nikolai V. Naoumov ${ }^{\star \ddagger}$ \\ *Institute of Liver Studies, King’s College School of Medicine \& Dentistry, London SE5 9PJ; ${ }^{\ddagger}$ Institute of Hepatology, University \\ College London Medical School, London WC1E GHX, United Kingdom; and ${ }^{\S}$ Department of Gastroenterology, University of \\ Heidelberg/Mannheim, 68167 Mannheim, Germany
}

\begin{abstract}
Interleukin-12, a cytokine with an important role against intracellular pathogens, promotes Th1 cell development, cellmediated cytotoxicity, and interferon- $\gamma$ production. We investigated the immunoregulatory role of IL-12 in 72 chronic hepatitis B virus (HBV) carriers, 33 of whom were monitored longitudinally during interferon- $\alpha$ treatment. Serum levels of IL-12 heterodimer, IL-12 p40 subunit, IL-4, and Th1 cytokines were determined by specific ELISAs, and hepatitis B core antigen-specific $\mathrm{T}$ cell response by a proliferation assay. Chronic HBV carriers had higher serum levels of IL-12 and IL-12 p40 in comparison with controls $(P<$ 0.01), suggesting that IL-12 production is not impaired. The longitudinal analysis revealed a further substantial increase ( $>2.5 \times$ baseline level) of bioactive IL-12 and Th1 cytokines in patients who cleared $\mathrm{HBV}$ and seroconverted to antihepatitis $\mathrm{B}$ e, unlike the 23 nonresponders with persistent HBV replication $(P<0.01)$. The IL-12 peak followed the peak of hepatocytolysis by $9.8 \pm 2.8 \mathrm{wk}$ and occurred either before or simultaneously with hepatitis B e seroconversion. Hepatitis B core antigen-specific $\mathrm{T}$ cell proliferation closely correlated with hepatocytolysis and increased significantly in all patients ( 8 responders and 15 nonresponders) who developed hepatitis flare, irrespective of the virological outcome. These results provide in vivo evidence that IL-12 may have an important role for viral clearance in chronic $\mathrm{HBV}$ infection. (J. Clin. Invest. 1997. 99:3025-3033.) Key words: interleukin-12 - hepatitis B virus - chronic hepatitis B • $\mathrm{T}$ helper cytokines $\bullet$ Th1/Th2 cells
\end{abstract}

\section{Introduction}

The host immune response to hepatitis $\mathrm{B}$ virus $(\mathrm{HBV})^{1}$ is a critical factor in determining the outcome of $\mathrm{HBV}$ infection. Patients with self-limited, acute hepatitis B develop strong

Address correspondence to N.V. Naoumov, M.D., Institute of Hepatology, University College London Medical School, 69-75, Chenies Mews, London WC1E 6HX, UK. Phone: 44-171-380 0401; FAX: 44171-380 0405.

Received for publication 23 July 1996 and accepted in revised form 26 March 1997.

1. Abbreviations used in this paper: ALT, alanine aminotransferase; CTL, cytotoxic T lymphocyte; HAI, histological activity index; HBcAg, hepatitis B core antigen; HBeAg, hepatitis B e antigen; HBsAg, hepatitis $B$ surface antigen; $\mathrm{HBV}$, hepatitis $\mathrm{B}$ virus; $\mathrm{HCV}$, hepatitis $\mathrm{C}$ virus; $\mathrm{POD}$, peroxidase-conjugated antibody; $\mathrm{SI}$, stimulation index.

J. Clin. Invest.

(C) The American Society for Clinical Investigation, Inc.

0021-9738/97/06/3025/09 \$2.00

Volume 99, Number 12, June 1997, 3025-3033 polyclonal HLA class I- and II-restricted T cell responses to viral peptides, while these responses are weak and narrowly focused in chronic HBV carriers (1). During the natural course of chronic HBV infection, some patients undergo a spontaneous exacerbation of the liver damage with elevation of serum aminotransferases, which may result in hepatitis $\mathrm{B}$ e antigen (HBeAg) to anti-HBe seroconversion and viral clearance. These hepatitis flares are associated with enhancement of the virus-specific $\mathrm{T}$ helper cell reactivity (2-4).

Recent studies have defined two T helper cell subsets, Th1 and $\mathrm{Th} 2$, which are characterized by distinct and mutually exclusive patterns of cytokine production and different functions (5). Th1 cells produce IFN- $\gamma$, IL-2, and promote cellular immune reactions, while Th2 cells produce IL-4, -5 , and -10 and enhance humoral immune response. Th1/Th2 imbalances are important in the pathogenesis of chronic viral infections in humans (6). Using sensitive, unconventional immunoassays, it has been shown that asymptomatic HBV carriers with high level of virus replication are characterized by Th2 type immune reactions, while exacerbations of chronic hepatitis B are associated with activation of Th1-type responses $(7,8)$. Thus, preferential activation and commitment towards Th1 or Th2 cell subsets would influence the clinical consequences of HBV infection.

Interleukin-12 is the dominant cytokine, which specifically promotes Th1 cell differentiation and suppresses Th2 function (6). Biologically active IL-12 is a heterodimer, composed of two subunits of 40 (p40) and 35 (p35) kD. IL-12 stimulates the production of IFN- $\gamma$ by peripheral blood mononuclear cells and augments natural killer cell cytotoxicity and antigen-specific proliferation of CD8+ cytotoxic T lymphocytes (CTL) $(9,10)$. Accumulating evidence suggests that this cytokine plays a central role in efficient immune response to bacterial and parasitic infections $(11,12)$ and can correct some of the deficient $\mathrm{T}$ cell responses in HIV-infected patients (13). The role of IL-12 in directing the immune responses in patients with chronic HBV infection has not been investigated.

The aim of our study was to investigate the immunoregulatory role of IL-12 for viral clearance in patients with chronic HBV infection. For this purpose, we longitudinally studied serum IL-12 levels, hepatitis B core antigen ( $\mathrm{HBcAg}$ )-specific $\mathrm{T}$ cell proliferation and markers of Th1 type response, IFN- $\gamma$ and IL-2, in chronic HBV carriers undergoing IFN- $\alpha$ treatment, which represents in a condensed time frame the process of HBV elimination. This allows a time course analysis of these immune reactions in relation to the exacerbation of hepatocytolysis and viral clearance, manifested by the alanine aminotransferase (ALT) flare and $\mathrm{HBeAg}$ to anti-HBe seroconversion, respectively.

\section{Methods}

Patients. The study examined 72 consecutive adults with chronic

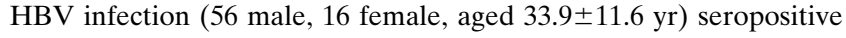


Table I. Biochemical and Histological Profile of Patients and Controls

\begin{tabular}{|c|c|c|c|c|}
\hline & Controls & Group 1 & Group 2 & Group 3 \\
\hline $\begin{array}{l}\text { Liver histology } \\
\text { HBV serology }\end{array}$ & HBsAg - ve & $\begin{array}{c}\text { Minimal histologic activity } \\
\text { HBeAg + ve } \\
\text { HBV DNA + ve }\end{array}$ & $\begin{array}{c}\text { Chronic active hepatitis } \\
\text { HBeAg + ve } \\
\text { HBV DNA + ve }\end{array}$ & $\begin{array}{c}\text { Minimal histologic activity } \\
\text { anti-HBe + ve } \\
\text { HBV DNA - ve }\end{array}$ \\
\hline Patient number & 23 & 27 & 26 & 19 \\
\hline Age & $30.8 \pm 6.9$ & $29.4 \pm 7.3$ & $36.2 \pm 13.6$ & $37.3 \pm 11.8$ \\
\hline Male/female & $26 / 19$ & $19 / 8$ & $23 / 3$ & $12 / 7$ \\
\hline Histological activity index & & $1.8 \pm 0.6$ & $5.46 \pm 2.3$ & $1.6 \pm 0.3$ \\
\hline Serum ALT (IU/ml) & $21.6 \pm 6.5$ & $32.6 \pm 14.6$ & $131.2 \pm 99.3$ & $24.1 \pm 5.1$ \\
\hline Serum HBV DNA (pg/ml) & & $233.0 \pm 214.3$ & $166.8 \pm 212.9$ & 0 \\
\hline
\end{tabular}

for hepatitis B surface antigen (HBsAg) for at least 12 mo. All patients were seronegative for markers of hepatitis $\mathrm{C}$ virus (HCV), hepatitis Delta virus, and HIV (Table I).

A percutaneous liver biopsy was performed in each patient as part of the diagnostic evaluation with informed consent. Liver histology was assessed blindly, with respect to serum aminotransferases and $\mathrm{HBe} \mathrm{Ag} / \mathrm{HBV}$ DNA status, on formalin-fixed paraffin sections, and the severity of necroinflammatory activity in the liver was assessed semiquantitatively (14). Portal tract inflammation, periportal piecemeal necrosis, and lobular inflammation were each graded on a 0-3 scale and a histological activity index (HAI) was calculated, with a maximum value of nine.

The patients were assigned to three distinct groups according to the degree of necroinflammatory activity and the presence of HBV replication. Group 1: 27 patients with active $\mathrm{HBV}$ replication (HBe $\mathrm{Ag}$ positive, anti-HBe negative, and HBV DNA positive), but only minimal histological activity in the liver biopsy (HAI 1-3), and normal or minimally elevated serum alanine aminotransferase (ALT $<1.5 \times$ upper limit of normal; normal range: 10-50 IU/liter). Group 2: 26 patients with active HBV replication, chronic active hepatitis B (with moderate or severe necroinflammatory activity, HAI 4-9) in the liver biopsy, and elevated serum ALT (ALT $>1.5 \times$ upper limit of normal). Group 3: 19 chronic HBsAg carriers with no serological evidence of ongoing viral replication (HBeAg negative, anti-HBe positive, and HBV DNA negative), minimal histological activity (HAI 1-3), and normal serum ALT for at least $12 \mathrm{mo}$, representing the final phase, the asymptomatic chronic carrier state. For comparison, sera from $23 \mathrm{HBsAg}$-negative healthy volunteers with normal liver function tests were tested as controls.

To analyze the time course of IL-12 and T helper cell responses in relation to $\mathrm{HBeAg}$ to anti-HBe seroconversion, $33 \mathrm{HBeAg}$ positive, anti-HBe negative, and HBV DNA positive patients (15 from Group 1 and 18 from Group 2; male, 30; female, 3) were studied at regular intervals before, during, and after IFN- $\alpha$ treatment. The median follow up was 21 mo (range 10-48) and serial samples from individual patients were analyzed (median 13 samples per patient, range 8-20). These patients were part of a clinical trial carried out with Ethics Committee approval. Recombinant IFN- $\alpha 2 b$ (Schering-Plough, Welwyn Garden City, UK) was given subcutaneously, 10 mega units, three times a week for 4 mo. A successful response to IFN- $\alpha$ was defined as a sustained loss of HBV DNA and HBeAg to anti-HBe seroconversion within 12 mo of completing treatment.

$I L-12$ and IL-12 p40 measurement. Serum levels of IL-12 heterodimer were determined by a specific ELISA using a rat monoclonal antibody (clone 20C2) reacting with a conformational epitope on the $75-\mathrm{kD}$ heterodimer IL-12 molecule. The IL-12 p40 chain was determined using a different primary antibody (clone 4A1). Both assays were performed as previously described (12) with minor modifications. Briefly, 96-well microtiter plates (Nunc Maxisorp, Roskilda, Denmark) were coated with $100 \mu \mathrm{l}$ of the primary monoclonal antibody against IL-12 or IL-12 p40 $(2.5 \mu \mathrm{g} / \mathrm{ml}$ in $0.01 \mathrm{M}$ bicarbonate buffer, $\mathrm{pH}$ 9.6), and incubated overnight at $4^{\circ} \mathrm{C}$. The coated plates were washed three times in deionized water and the remaining nonspecific protein binding capacity of the wells was blocked with $0.5 \%$ bovine serum albumin in phosphate buffered saline, $\mathrm{pH} 7.4$, overnight at $4^{\circ} \mathrm{C}$. Serum samples, diluted $1: 5$, and serial dilutions of the recombinant standards (IL-12 or IL-12 p40) were added to the plates and incubated for $2 \mathrm{~h}$ at $20^{\circ} \mathrm{C}$. After washing with PBS buffer containing $0.05 \%$ Tween 20, $100 \mu \mathrm{l}$ of secondary antibody (clone 4D6-POD, working concentration $125 \mathrm{ng} / \mathrm{ml}$ ) was added for $2 \mathrm{~h}$. The enzyme reaction was developed using $100 \mu \mathrm{l}$ of $10 \mathrm{mmol} /$ liter tetramethylbenzidine, $80 \mathrm{mmol} /$ liter $\mathrm{H}_{2} \mathrm{O}_{2}$, and $30 \mathrm{mmol} /$ liter potassium citrate, $\mathrm{pH} 4.1$. After a 10-min incubation at room temperature, the reaction was terminated with $50 \mu \mathrm{l}$ of $1 \mathrm{M} \mathrm{H}_{3} \mathrm{PO}_{4}$, and the optical density read at $450 \mathrm{~nm}$ (MR 700 automated plate reader; Dynatech Laboratories, Inc., Chantilly, VA).

Each sample was tested in duplicate and the values determined from the standard curve (range $0-800 \mathrm{pg} / \mathrm{ml}$ ), constructed using the serial dilutions of recombinant IL-12 or IL-12 p40 standards. The detection limit was $<10 \mathrm{pg} / \mathrm{ml}$ with the intra- and inter-assay variances for both ELISAs being $6.3 \pm 2.5$ and $11.3 \pm 3.5 \%$, respectively.

The IL-12 heterodimer-specific ELISA showed no cross-reactivity with other recombinant cytokines or cytokine receptors (IL-12 p40, IL-2, IFN $\gamma$, IL-4, TNF- $\alpha$, or recombinant TNF receptors) over a wide range of concentrations $(0.1 \mathrm{pg} / \mathrm{ml}-1 \mu \mathrm{g} / \mathrm{ml})$. In patients with high serum levels of IL-12, ELISA testing was repeated with serial dilutions (1:5-625) to exclude the possibility of false positive results, which may arise with inadequate dilution. Furthermore, the specificity of the ELISA detection method was verified by the addition of recombinant IL-12 (50-500 pg/ml) to sera with high levels of IL-12. The detection of this added recombinant IL-12 confirmed that the high levels of endogeneous IL-12 in certain samples was not due to interference with unknown serum components.

The IL-12 p40-specific ELISA showed 20-25\% cross-reactivity with recombinant IL-12 heterodimer, demonstrating that the antibody epitope of the $\mathrm{p} 40$ chain was recognized as part of the IL- 12 heterodimer. With the available antibody specific for IL-12 p40 (clone $4 \mathrm{~A} 1$ ), it was not possible to differentiate various forms of IL-12 p40 (monomer, homodimer, or as part of the IL-12 heterodimer).

Assays for Th1 and Th2 cytokines. Serum IFN- $\gamma$, IL-2, and IL-4 levels were measured with sandwich ELISAs, each using two mAbs directed to different epitopes (for IFN- $\gamma$ mAbs, clones 69 and 69 peroxidase-conjugated antibody (POD); for IL-2 mAbs, clones 3D5/7B1 and 13A6 POD; for IL-4 mAbs, clones 5 and 4F2 POD; kindly donated by Dr. H. Gallati, Hoffmann-La Roche, Basel, Switzerland) as previously described $(2,15)$. Serum samples, diluted $1: 5$, were compared with serial dilutions of recombinant standards IFN- $\gamma$ (specific activity $2 \times 10^{8} \mathrm{U} / \mathrm{mg}$ ), IL-2, and IL-4. The incubation with the mAbs for IFN- $\gamma$ and IL- 2 was for $24 \mathrm{~h}$ at $2-8^{\circ} \mathrm{C}$, and for IL-4 at $20-22^{\circ} \mathrm{C}$. OD readings were performed at $450 \mathrm{~nm}$. The ELISAs were sensitive to IFN- $\gamma$ levels above $30 \mathrm{pg} / \mathrm{ml}$, IL-2 levels above $20 \mathrm{pg} / \mathrm{ml}$, and IL-4 levels above $15 \mathrm{pg} / \mathrm{ml}$. The inter- and intraassay coefficients of variation 
were 8 and $5 \%$ for the IFN- $\gamma$ assay, $5-12$ and 3-7\% for the IL- 12 assay, and 5-8 and $9 \%$ for the IL-4 assay. The specificity of the assays were confirmed by checking the assays against other human cytokines $(500 \mathrm{pg} / \mathrm{ml}$ recombinant TNF- $\alpha$ IL- $1 \alpha$, IL-1 $\beta$, and IL-6), which showed no cross-reactivity.

PBMC proliferation assay. PBMCs were separated by standard density gradient centrifugation with 'Lymphoprep' (Nyegaard, Oslo, Norway). The cells were cultured at $2 \times 10^{5}$ cells/well in buffered RPMI 1640 supplemented with $10 \%$ (vol/vol) heat-inactivated human AB serum (Lot 1652; Gemini Bio-Products Inc., Calabasas, CA) in 96-well, flat-bottomed sterile microtiter plates (Nunclon; GIBCO BRL, Glasgow, UK) for $5 \mathrm{~d}$ at $37^{\circ} \mathrm{C}$ in a humidified atmosphere of $5 \% \mathrm{CO}_{2}$ in air, as previously described (2). Briefly, the cell culture was performed in the presence or absence of $1 \mu \mathrm{g} / \mathrm{ml}$ recombinant $\mathrm{HBcAg}$ (rHBcAg; Wellcome Research Laboratories, Beckenham, Kent, UK) in complete medium (buffered RPMI 1640 supplemented with $10 \% \mathrm{AB}$ serum). Each well was pulsed with $0.5 \mu \mathrm{Ci}$ tritiated Thymidine (Amersham International, Little Chalfont, UK) $16 \mathrm{~h}$ before harvesting. The cells were washed and harvested onto glass fiber filters (Packard Instruments, Groningen, The Netherlands) using an automated cell harvester. The amount of radiolabel incorporated into DNA was measured by a direct beta counter (Matrix 9600; Packard Instruments). The proliferation assay was performed in 12 replicates and the results expressed as the mean counts per minute. The stimulation index (SI) was calculated by dividing the cpm for the antigenstimulated cultures by that of control cultures (PBMCs with complete medium only). An SI greater than two times the mean plus 2 SD for the 23 healthy controls (i.e., an SI > 2.5) was considered significant.

To determine the HLA restriction of the PBMC proliferative response to recombinant $\mathrm{HBcAg}$, blocking experiments with monoclonal anti-HLA antibodies (kindly provided by Dr. P. Banga, Department of Medicine, King's College, London) were performed. Monoclonal antibodies recognizing HLA class I (W6/32) and class II determinants to DR (L243), DP (B7/21), DQw1 (4D4), DQw2 (C1A2), and DQw3 (1VD12) were each added separately to the PBMC and antigen mixture, at three different final dilutions of $1: 6,1: 12$, and $1: 24$. The PBMC-proliferative response to $\mathrm{rHBcAg}$ was significantly inhibited in a dose-dependent manner by the antibody directed to HLA DR, demonstrating that the cellular response was HLA class II restricted.

Hepatitis serology. $\mathrm{HBsAg}, \mathrm{HBeAg}$, anti-HBe, anti-hepatitis Delta virus, anti-HCV, and anti-HIV were tested using commercially available assays (Abbott Diagnostics, Maidenhead, UK; Sorin Biomedica, Saluggia, VC, Italy, and UBI HCV EIA; United Biochemical Inc., Lake Success, NY). Serum HBV DNA was measured using a solution hybridization assay (Genostics; Abbott Diagnostics, Maidenhead, UK).

Statistical analysis. Nonparametric tests were used to analyze the results of the SI and the serum levels of IL-12, IL-12 p40, IFN- $\gamma$, IL-2, and IL-4. In particular, the Mann-Whitney U test was employed to compare data between two groups and the nonparametric Wilcoxon's matched pairs test was used to compare two sets of data in the same group. Correlation analysis was performed using the Spearman's rank-regression coefficient. The Chi-square test $\left(\chi^{2}\right)$ was used to compare the prevalence or distribution of two variables in the same group. Data are presented as mean \pm SEM. $P<0.05$ was considered statistically significant.

\section{Results}

Serum levels of IL-12, IL-12 p40, and Th cytokines. The serum levels of both IL-12 and IL-12 p40 subunit were significantly higher in the cohort of patients with chronic HBV infection studied $(n=72)$ in comparison with control subjects (mean \pm SEM for IL-12, $57.5 \pm 8.8$ vs. $9.9 \pm 1.1 \mathrm{pg} / \mathrm{ml}$; IL-12p40, $147.1 \pm 10.2$ vs. $78.8 \pm 6.1 \mathrm{pg} / \mathrm{ml}, P<0.01$ Mann Whitney-U). Normally, the production of IL-12 p40 heavy chain exceeds the production of IL-12 heterodimer between 10- and 50-fold (6). To evaluate the proportion between IL-12 p40 and the biologically active IL-12 heterodimer, we calculated the ratio between their values detected at the same time point in individual patients and controls. Patients with chronic HBV infection showed a significantly lower ratio of IL-12 p40/IL-12 in comparison with noninfected controls $(6.1 \pm 0.8$ vs. 12.1 \pm 1.6 , mean \pm SEM, $P<0.01$ Mann Whitney-U). When this ratio was analyzed between different groups of chronic HBV carriers, there was no significant difference between the three groups of patients irrespective of their histological activity or virus replication (IL-12 p40/IL-12 heterodimer ratio for groups 1, 2, and $3,5.5 \pm 0.9,4.4 \pm 0.8$, and 7.1 \pm 1.9 , respectively, mean \pm SEM).

The serum levels of the Th1 cytokines IFN- $\gamma$ and IL-2 were significantly higher in patients with chronic hepatitis B infection compared with controls (mean \pm SEM for IFN- $\gamma, 75.1 \pm 8.6$ vs. $5.5 \pm 0.7 \mathrm{pg} / \mathrm{ml}$; for IL-2, $3.7 \pm 0.4$ vs. $1.2 \pm 0.1 \mathrm{ng} / \mathrm{ml}$, respectively, $P<0.01$ Mann Whitney-U). The analysis between different groups of chronic HBV carriers showed that patients with high necroinflammatory activity (group 2) have significantly higher serum levels of both IL-2 and IFN- $\gamma$ when compared with chronic HBV carriers with minimal histological activity (groups 1 and 3 ) or to control subjects (for all $P<0.01$, Fig. 1). The serum levels of both IL-2 and IFN- $\gamma$ in patients from group 1 were higher than controls $(P<0.01)$, while in patients from group 3 , only IFN- $\gamma$ levels differed significantly from the levels detected in controls. There was no difference in the serum levels of IL-4 between chronic HBV carriers and controls $(92.7 \pm 14.1$ and $74.8 \pm 2.8 \mathrm{pg} / \mathrm{ml}$, respectively, mean \pm SEM)

Longitudinal analysis of IL-12 and IL-12 p40 in chronic $H B V$ infection. 10 of 33 patients responded to IFN- $\alpha$ with $\mathrm{HBe} \mathrm{Ag}$ to anti-HBe seroconversion and sustained loss of serum HBV DNA within 12 mo of completing treatment (three from group 1 and seven from group 2). 8 of these 10 patients

\section{$\operatorname{IFN} \gamma(\mathrm{pg} / \mathrm{ml})$}
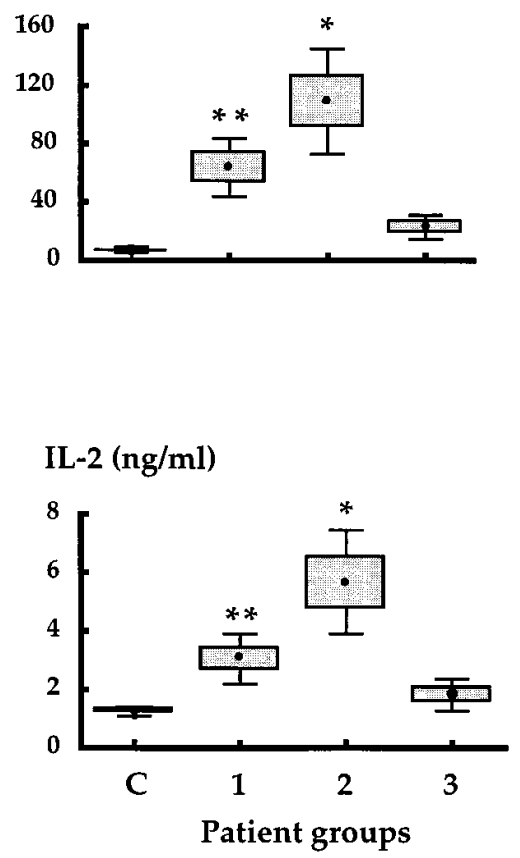

Figure 1. Serum levels of Th1 cytokines in three groups of chronic HBV carriers. C, control subjects; group 1, patients with active viral replication and minimal histological activity; group 2, patients with active viral replication and moderate to severe necroinflammatory activity; group 3, HBsAgpositive patients without viral replication and no necroinflammatory activity. *Significantly higher than groups 1 and 3 , and controls $(P<0.01)$; **Significantly higher than group 3 and controls. 


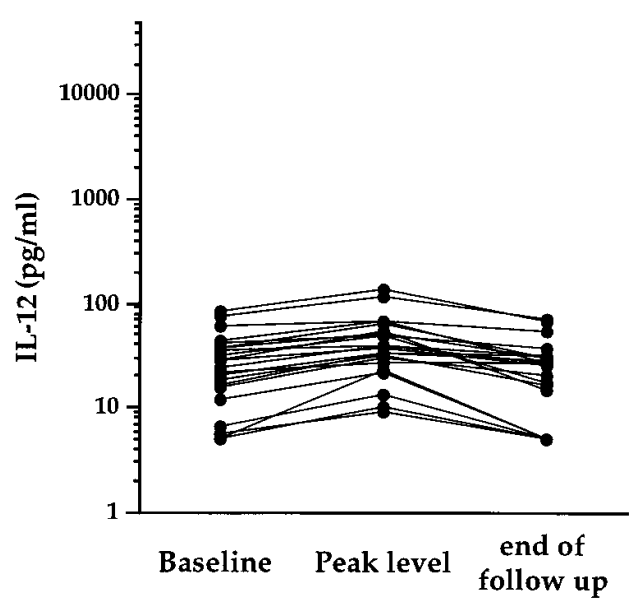

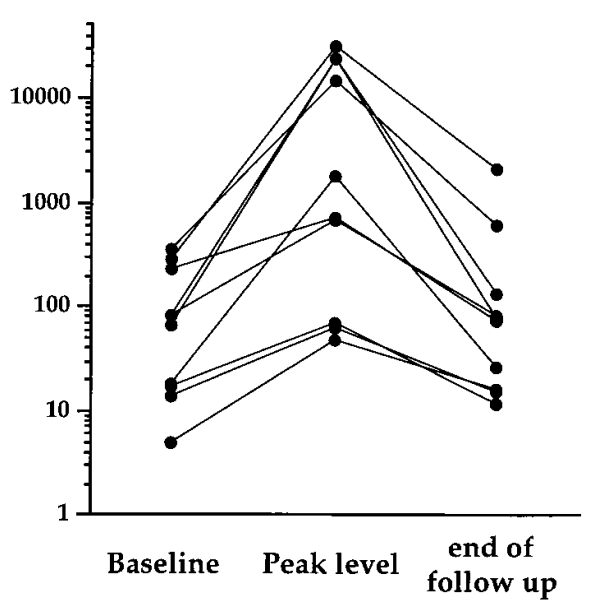

Figure 2. Serial analysis of serum levels of IL-12 in chronic HBV carriers in relation to response to IFN- $\alpha$ treatment. The serum levels of IL-12 heterodimer are shown before the treatment (Baseline), the peak serum IL-12 detected during the period of the study and 12 mo after the end of treatment (end of follow up). IL-12 levels increased more than 2.5-fold in all patients with chronic hepatitis B who seroconverted to anti-HBe, while this was observed in only one of the 23 nonresponders. developed a characteristic hepatitis flare in association with IFN- $\alpha$ treatment (peak ALT level, 396.5 $\pm 80.3 \mathrm{IU} / \mathrm{ml}$, mean \pm SEM), which preceded the time of seroconversion. A similar flare was observed in 15 of the 23 nonresponders to IFN- $\alpha$ therapy (peak ALT level, 283.1 $\pm 59.8 \mathrm{IU} / \mathrm{ml}$, mean \pm SEM).

The pretreatment serum levels of the IL-12 heterodimer were significantly higher among the responders to IFN- $\alpha$ in comparison with the nonresponders (pretreatment IL-12, $116.9 \pm 39.6$ vs. $28.1 \pm 4.5 \mathrm{pg} / \mathrm{ml}$, respectively, $P<0.01$, MannWhitney U test), whereas there was no significant difference between the pretreatment IL-12 p40 levels. The pretreatment IL-12 p40/IL-12 heterodimer ratio was significantly lower among the responders compared with nonresponders $(2.8 \pm 0.8$ vs. $8.1 \pm 1.4$, mean \pm SEM) $(P<0.01$, Mann-Whitney U test $)$. Furthermore, all 10 patients who seroconverted to anti-HBe showed $>2.5$-fold increase in serum IL-2 either during treatment or in the posttreatment follow-up period. In 7 of these 10 patients, the peak serum IL-12 reached levels $>500 \mathrm{pg} / \mathrm{ml}$ (Fig. 2). Among the 23 nonresponders, only one patient developed a rise in serum IL-12 $>2.5$-fold above the corresponding pretreatment level (from $5 \mathrm{pg} / \mathrm{ml}$ at baseline to $20 \mathrm{pg} / \mathrm{ml}$ peak level) and in none of the nonresponders did the peak serum
IL-12 level reach above $200 \mathrm{pg} / \mathrm{ml}$ (Chi-square 20.4, $P<0.01$ ). The peak IL-12 level in the 10 responders was significantly higher in comparison with the peak level reached by the 15 nonresponders who had an ALT flare (12,232.7 $\pm 4,635.3$ vs. $50.9 \pm 9.4 \mathrm{pg} / \mathrm{ml}$, mean \pm SEM, $P<0.01$, Mann-Whitney U test).

Although the IL-12 p40 levels showed some increase during the period of longitudinal analysis, there were no significant differences between the changes observed in the responders and nonresponders (Fig. 3). The IL-12 p40/IL-12 heterodimer ratio was substantially reduced at the time of the peak serum IL-12 concentration among the 10 patients who seroconverted to anti-HBe as there was no parallel increase in IL-12 p40. In contrast, the ratio remained unchanged in the nonresponders, irrespective of whether or not there was an ALT flare (Fig. 4).

Patients who seroconverted to anti-HBe showed a marked elevation in the serum levels of IL-2 and IFN- $\gamma$ either during $(n=7)$ or after $(n=3)$ the end of treatment. In 7 of the 10 responders, the increase of serum IFN- $\gamma$ level was $>2.5 \times$ in comparison with the corresponding pretreatment level, whereas only 3 of the 23 nonresponders had such a significant increase in serum IFN- $\gamma$ (Chi-square 10.7, $P<0.01$ ) (Fig. 5). Similarly,

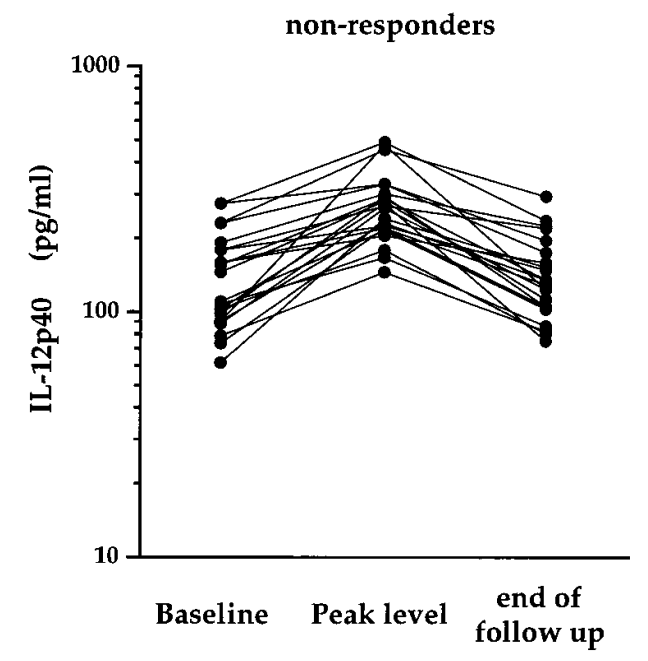

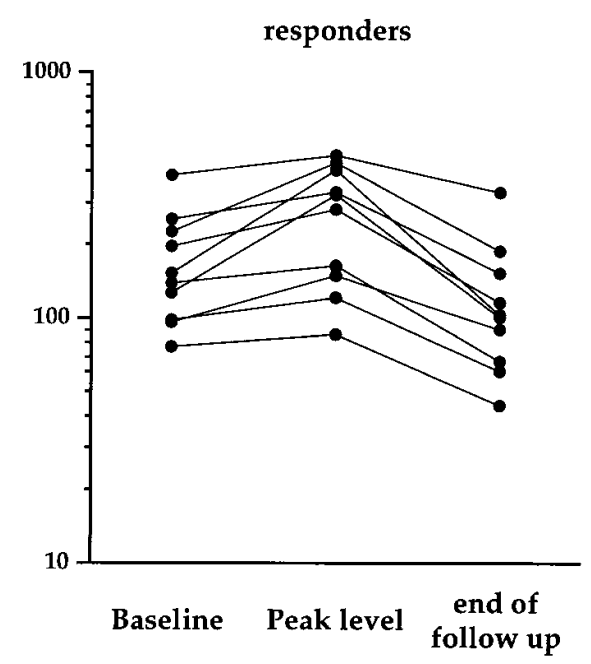

Figure 3. Serial analysis of serum levels of IL-12 p40 in chronic HBV carriers in relation to the response to IFN- $\alpha$ treatment. There were no significant differences between patients who seroconverted to anti$\mathrm{HBe}$ (responders) and nonresponders to IFN- $\alpha$ treatment. 


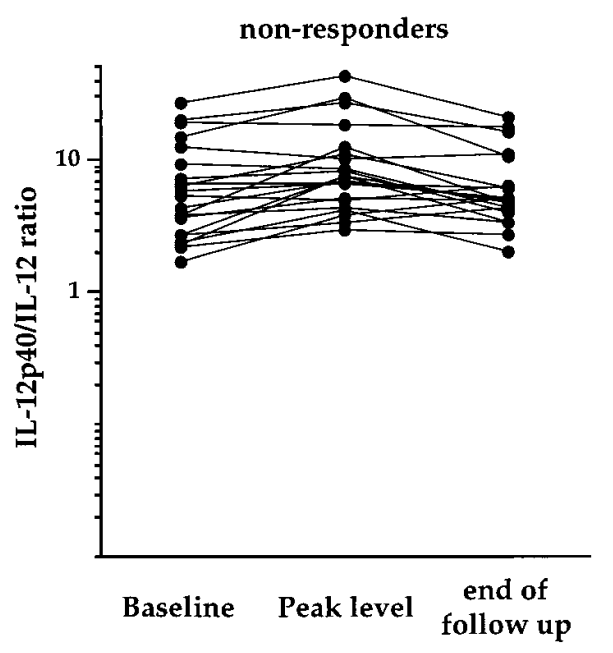

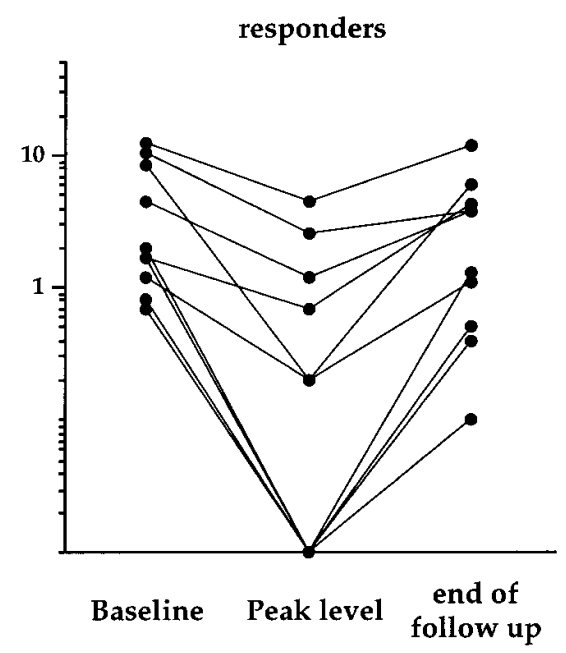

Figure 4. Changes in the ratio of serum IL-12 p40/IL-12 heterodimer during serial analysis of chronic HBV carriers treated with IFN- $\alpha$. At the time of the highest serum IL-12 level for each patient, the ratio decreased significantly $(P<0.01)$ only in patients who seroconverted to anti-HBe. a significant rise in serum IL-2 levels $(>2.5 \times$ pretreatment level) was observed in 7 of 10 responders during or immediately after IFN- $\alpha$ treatment. In 8 of 10 patients, the peak serum IL-2 level was $>5 \mathrm{ng} / \mathrm{ml}$. In contrast, only 5 of the 23 nonresponders had peak serum IL-2 levels above $5 \mathrm{ng} / \mathrm{ml}$ (Chisquare 9.9, $P<0.01$ ) (Fig. 6).

$H B c A g$-specific proliferative response during IFN- $\alpha$ treatment. 23 patients developed a significant rise in $\mathrm{HBcAg}$-specific $\mathrm{T}$ cell-proliferative response during IFN- $\alpha$ treatment ( 8 responders and 15 nonresponders), and all of them showed a hepatitis flare. There was no difference in the peak SI between responders $(n=8)$ and nonresponders $(n=15)$ (peak SI, $4.87 \pm 0.46$ and $4.17 \pm 0.49$, respectively, mean \pm SEM). In contrast, only 2 of the remaining 10 patients who did not show an ALT flare developed an increase in $\mathrm{T}$ cell-proliferative response during IFN- $\alpha$ treatment (peak SI, 2.15 \pm 0.2 , mean \pm SEM, $n=10$ ). Among the 23 patients with a significant rise in the $\mathrm{HBcAg}$-specific proliferative response, the peak SI preceded the peak of the ALT rise in 16 patients, with a mean interval between the peak SI and peak ALT of $6.9 \pm 1.1 \mathrm{wk}$. In the remaining seven patients, the peak SI coincided with the peak of serum ALT.

Time course of cytokine profiles in relation to hepatitis flare and viral clearance. In the eight patients who developed an ALT flare and seroconverted to anti-HBe, we analyzed the sequence of events in relation to serum levels of the cytokines. In all eight patients, there was a significant rise in serum IL-12 with the peak IL-12 level following the ALT peak by a mean period of $9.8 \pm 2.8 \mathrm{wk}$. When this IL-12 rise was analyzed in relation to the time of $\mathrm{HBeAg}$ to anti-HBeAg seroconversion, the serum IL-12 peak occurred either simultaneously $(n=2)$ or preceded the seroconversion by $9.3 \pm 1.0 \mathrm{wk}(n=6)$. In all eight patients, the IL-12 levels declined rapidly thereafter. At the time of serum IL-12 rise, there was a significant increase in serum IFN- $\gamma$ and IL-2 levels that also preceded or coincided with the time seroconversion (Fig. 7). In patients who did not seroconvert, no significant changes in the serum levels of IL-12, IFN- $\gamma$, or IL- 2 were detected during the follow-up period, regardless of whether there was or wasn't an ALT flare (Figs. 8 and 9).

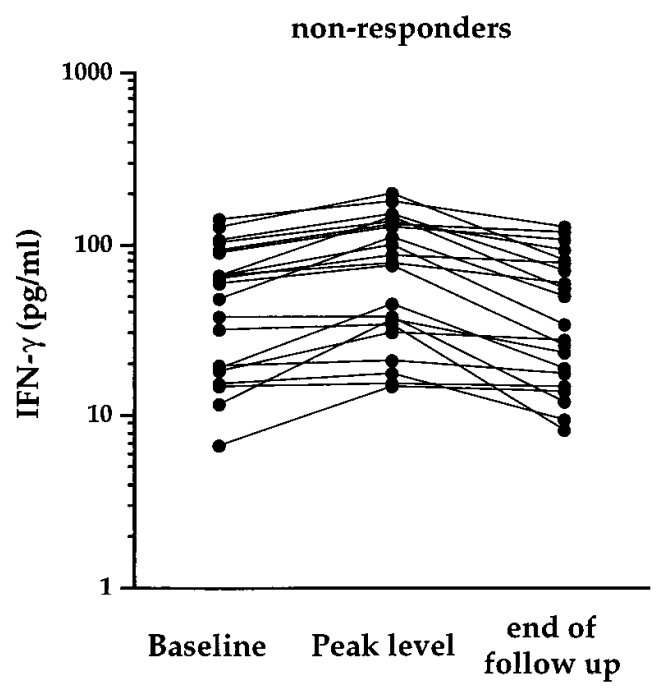

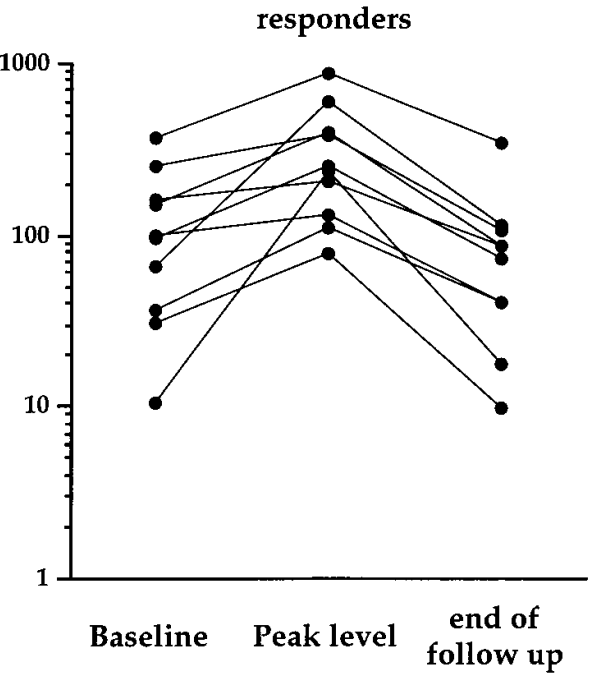

Figure 5. Longitudinal analysis of IFN- $\gamma$ serum levels in chronic HBV carriers in relation to the outcome of IFN- $\alpha$ treatment. The majority of patients who seroconverted to anti-HBe showed $>2.5$-fold increase in IFN- $\gamma$ level in contrast with nonresponders. 


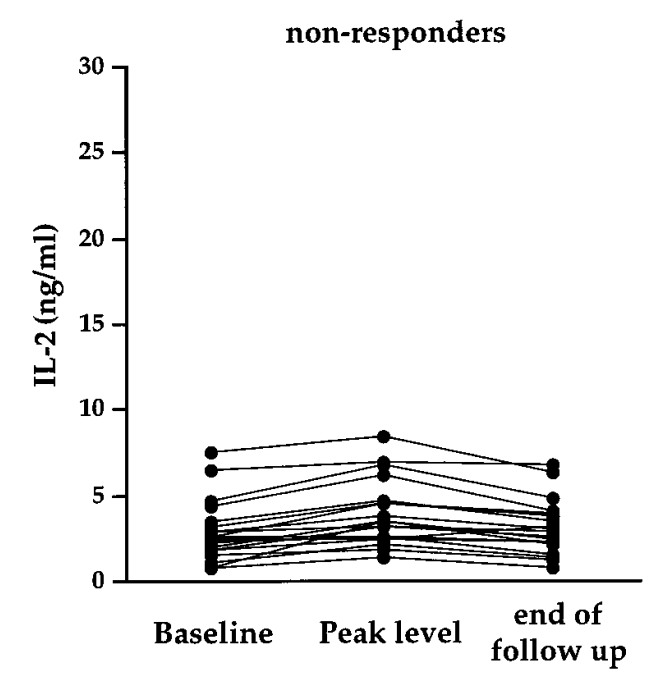

Figure 6. Longitudinal analysis of serum IL-2 levels in chronic HBV carriers in relation to the outcome of IFN- $\alpha$ treatment. Serum IL-2 levels increased significantly in patients with chronic hepatitis B who seroconverted to anti-HBe.

\section{Discussion}

The present study indicates that, although immune-mediated hepatocytolysis is a critical initial event in the process of viral clearance, a substantial increase in IL-12 production, along with the induction of Th1 cytokines (IFN- $\gamma$, IL-2), is required for a sustained immune control over HBV replication, manifested by seroconversion to anti-HBe. Thus, these results provide the first in vivo evidence that IL-12 may contribute to viral clearance in chronic HBV infection.

The finding that the peak of serum IL-12 levels in patients who seroconverted to anti-HBe occurred consistently after the hepatitis flare was unexpected. Several elements in the longitudinal analysis demonstrate the specificity of this observation. First, the substantial increase in IL-12 production practically occurred only in patients who seroconverted to anti-HBe and during the long follow-up period (median 21 mo, range 10-48) this was the only peak in serum IL-12 in each of these patients. The IL-12 rise was associated with a significant increase in Th1 cytokines, and high levels of IFN- $\gamma$ and IL-2 were observed in these patients. Second, despite the fact that a similar degree of hepatocytolysis developed in 15 of the other 23 interferontreated patients who remained seropositive for $\mathrm{HBeAg}$, only one showed some IL-12 elevation during the entire follow-up. Third, the specificity of ELISA detection of IL-12 heterodimer was carefully verified by the lack of cross-reactivity with other cytokines, testing serial dilutions of the positive samples and by spiking experiments with the addition of recombinant IL-12.

The dissociation between the mechanisms responsible for the immune-mediated hepatocytolysis and for viral clearance in HBV infection was first proposed by F. Chisari and his group, based on their work with a transgenic mouse model (16). It was demonstrated that the interaction between antigen-specific CTL and target hepatocytes results in spotty necrosis, which is limited to a very few hepatocytes (17). Instead, the antiviral effect is mediated by IFN- $\gamma$, IL- 2 , and TNF- $\alpha$ released by HBV-specific CTLs, and these cytokines profoundly suppress HBV gene expression in infected hepatocytes by noncytolytic mechanisms (18-21). In a recent study using transgenic mice that replicate the entire HBV genome, they have further demonstrated that IFN- $\gamma$ and TNF- $\alpha$, secreted by
CTL or by antigen nonspecific macrophages, activate two independent virocidal pathways; the first eliminates HBV nucleocapsid particles and the second destabilizes the viral RNA (22). Thus, after recognition of HBV antigens on the surface of infected hepatocytes, CTLs perform two distinct functions; they kill a small fraction of infected hepatocytes and they secrete IFN- $\gamma$ and TNF- $\alpha$, which exert antiviral effects without destruction of hepatocytes. Effective clearance of duck HBV and woodchuck hepatitis virus has also been shown to occur without massive hepatocellular necrosis $(23,24)$.

The results in the present study demonstrate that a dissociation between immune-mediated hepatocytolysis and viral clearance also exists in patients with chronic HBV infection. Although we have not studied the local cytokine production in $\mathrm{HBV}$-infected livers, the advantage of our longitudinal analysis is that it provides an understanding of the temporal relationship between changes in HLA class II-restricted T cell responses, the levels of heterodimer IL-12, IL-12 p40, and Th1 cytokines in relation to hepatocellular necrosis and HBV clearance in patients with chronic HBV infection. Both spontaneous or interferon-induced exacerbations of hepatocellular necrosis in chronic hepatitis $\mathrm{B}$ have previously been shown to be associated with an induction of $\mathrm{HBcAg}$-specific, CD4+ $\mathrm{T}$ cell response $(2,3,25)$. In agreement with these observations, the virus-specific $\mathrm{T}$ helper cell proliferation was enhanced in all 23 patients with hepatitis flare in the present study, irrespective of whether or not $\mathrm{HBe}$ seroconversion followed, and occurred either before or simultaneously with the ALT peak. In contrast, a significant increase in IL-12 production was observed only in patients who cleared the virus. This rise in serum IL-12 and Th1 cytokines always followed the ALT flare, but preceded the time of $\mathrm{HBeAg}$ to anti-HBe seroconversion. IL-12 is produced by phagocytic cells, B lymphocytes, and other antigen-presenting cells (6). A possible explanation of why the IL-12 peak occurs after the ALT flare would be that hepatocellular necrosis, induced by CTL, leads to the recruitment of macrophages and noncommitted $\mathrm{T}$ helper cells in the liver. Native particles of $\mathrm{HBcAg}$ are released from damaged hepatocytes and provide potent antigenic stimulation for these cells. In patients able to respond with an increase in IL-12 production, this will promote Th1 cell development and will 


\section{Responder with ALT flare}
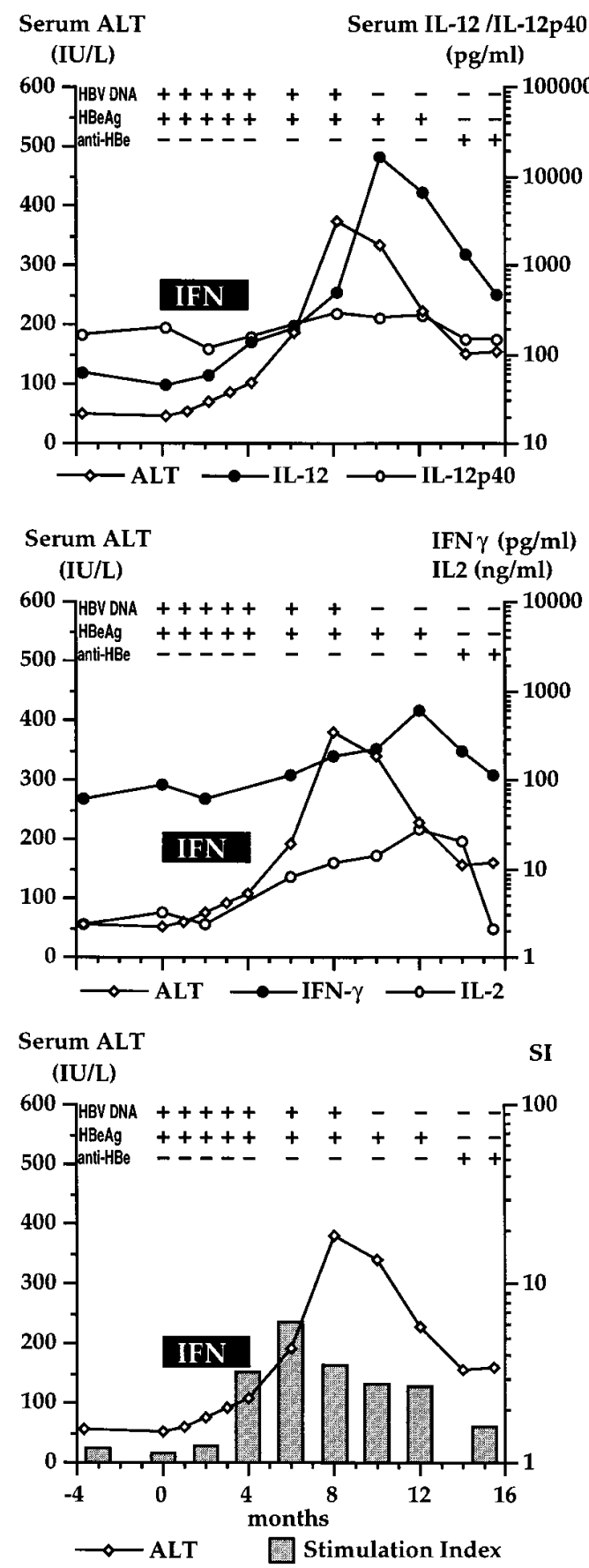

Figure 7. Time-course analysis of IL-12, IL-12 p40, Th1 cytokines, and $\mathrm{HBcAg}$-specific T cell-proliferative response in relation to hepatocytolysis in a chronic HBV carrier with $\mathrm{HBeAg}$ to anti-HBe seroconversion as a result of IFN- $\alpha$ treatment (IFN, treatment with IFN- $\alpha$ ). The peak of serum IL-12 was associated with a significant rise in serum IL-2 and IFN $\gamma$ level. The IL-12 peak preceded the time of seroconversion to anti-HBe.

stimulate the production of IFN- $\gamma$ and TNF- $\alpha$, which will exert their noncytolytic antiviral effects. Importantly, responders to IFN- $\alpha$ therapy had significantly higher pretreatment levels of serum IL-12 in comparison with chronic HBV carriers who
Non-Responder with ALT flare
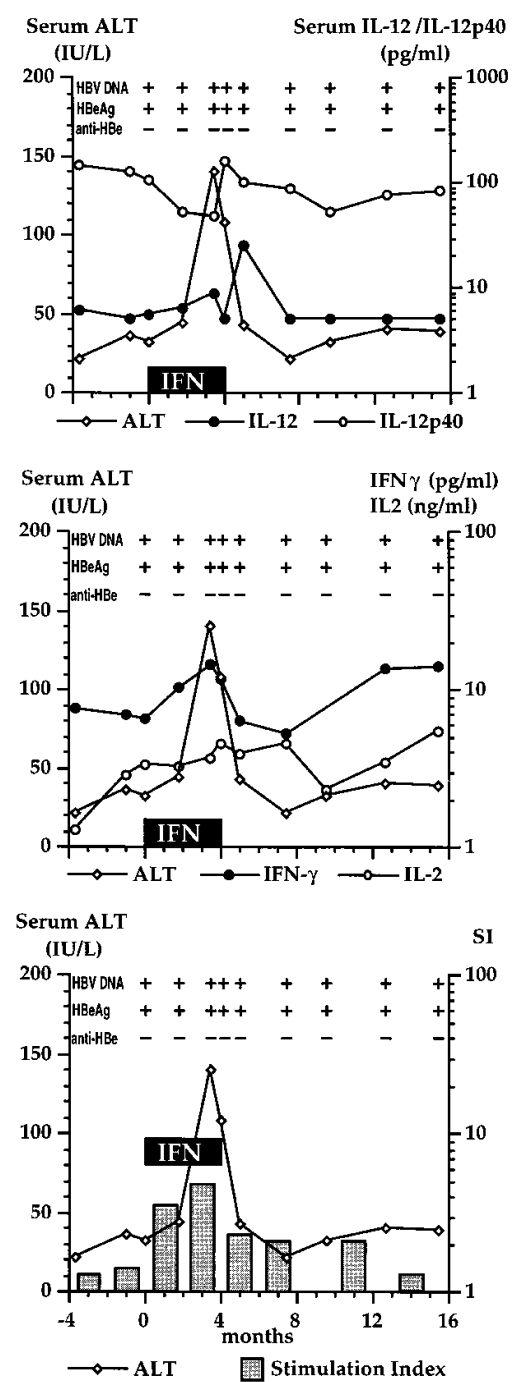

Figure 8. Time-course analysis of IL-12, IL-12 p40, Th1 cytokines, and HBcAg-specific T cellproliferative response in a chronic HBV carrier with significant hepatocytolysis during IFN- $\alpha$ treatment but without seroconversion to anti-HBe.

failed the treatment. Further investigations are needed to determine the factors responsible whether or not a chronic HBV carrier will augment the IL-12 production sufficiently to induce viral clearance as a result of IFN- $\alpha$ treatment. Another marker of a direct stimulation of $\mathrm{B}$ cells by $\mathrm{HBcAg}$ released from damaged hepatocytes is the rise of serum $\operatorname{IgM}$ anti-HBc during exacerbations of chronic hepatitis $\mathrm{B}$, and we have previously shown that the peak IgM anti-HBc follows the peak of hepatocytolysis by $3-8 \mathrm{wk}$ (26).

The bioactive molecule of IL-12 is a heterodimer, produced along with its larger component, IL-12 p40, which is highly regulated and secreted in response to bacteria, bacterial products, and intracellular pathogens (6). The present study is the first report on serum IL-12 and IL-12 p40 levels and the kinetics of their changes during the course of chronic HBV infection. The longitudinal analysis revealed that before $\mathrm{HBe}$ seroconversion there is a rapid and substantial increase in the IL-12 heterodimer in the serum, which for a short period of time results in an inverse IL-12 p40/IL-12 ratio. All chronic HBV carriers have very high serum levels of anti-HBc antibodies and detectable levels of anti-HBe and -HBs were found in $>50 \%$ of 


\section{Non-Responder without ALT flare}
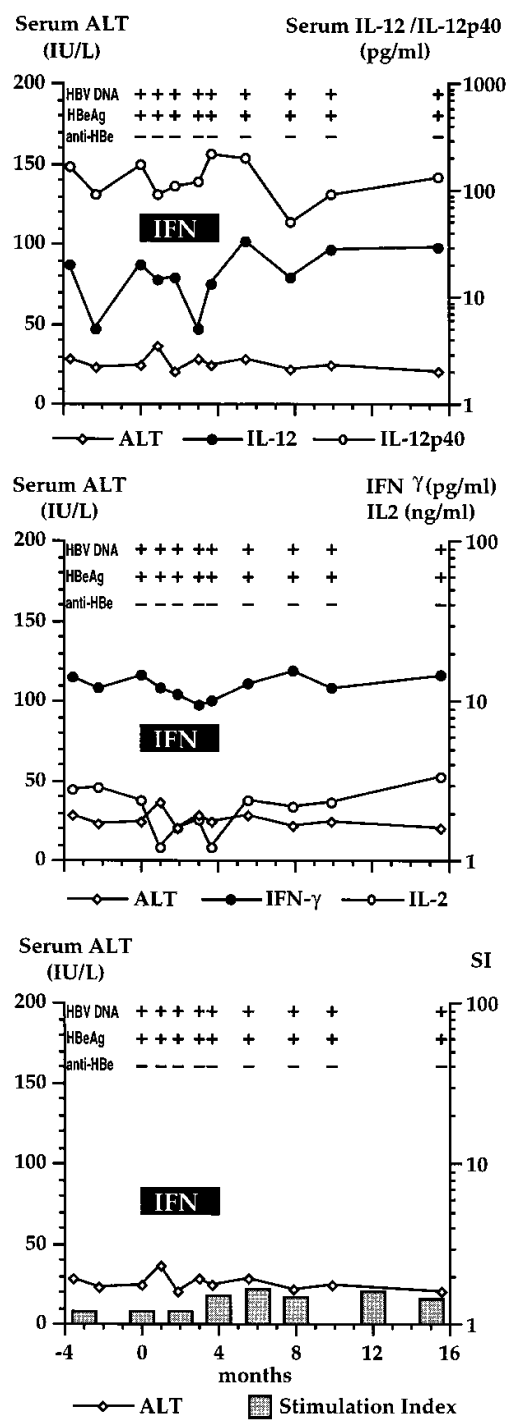

with chronic HBV infection support a previously proposed combination strategy with IL-12 plus therapeutic vaccination (28). Based on the ability of IL-12 to induce antigen-dependent Th1 differentiation and CTL proliferation (30), a combination of recombinant IL-12 and recombinant, particulate $\mathrm{HBcAg}$ may provide a specifically targeted immunotherapy in chronic carriers with ongoing HBV replication.

\section{Acknowledgments}

The authors thank Dr. Maurice K. Gately, Hoffmann La Roche (Nutley, NJ) for providing the monoclonal antibodies to IL-12, and Dr. Francis V. Chisari for his constructive comments on the manuscript.

S. Rossol was supported by the Alexander von Humboldt Foundation (Bonn, Germany). P. Carucci was supported by the Associazione Italiana Copev (Milan, Italy). Part of the work was supported by grant 64/95 (S. Rossol) from the Faculty of Clinical Medicine (Mannheim, Germany).

\section{References}

1. Chisari, F.V., and C. Ferrari. 1995. Hepatitis B virus immunopathogenesis. Annu. Rev. Immunol. 13:29-60.

2. Marinos, G., F. Torre, S. Chokshi, M. Hussain, B.E. Clarke, D.J. Rowlands, A.L. Eddleston, N.V. Naoumov, and R. Williams. 1995. Induction of T-helper cell response to hepatitis B core antigen in chronic hepatitis B: a major factor in activation of the host immune response to the hepatitis B virus. Hepatology. 22:1040-1049.

3. Tsai, S.L., P.J. Chen, M.Y. Lai, P.M. Yang, J.L. Sung, J.H. Huang, L.H Hwang, T.H. Chang, and D.S. Chen. 1992. Acute exacerbations of chronic type $\mathrm{B}$ hepatitis are accompanied by increased $\mathrm{T}$ cell responses to hepatitis B core and e antigens. J. Clin. Invest. 89:87-96.

4. Löhr, H.F., W. Weber, J. Schlaak, B. Goergen, K.H. Meyer zum Büschenfelde, and G. Gerken. 1995. Proliferative response of CD4+ T cells and hepatitis B virus clearance in chronic hepatitis with or without hepatitis B e-minus hepatitis B virus mutants. Hepatology. 22:61-68.

5. Paul, W.E., and R.A. Seder. 1994. Lymphocyte responses and cytokines.
Figure 9. Time-course analysis of IL-12, IL-12 p40, Th1 cytokines, and HBcAg-specific T cellproliferative response in a chronic HBV carrier with no ALT flare and no response to IFN- $\alpha$ treatment. the asymptomatic viremic patients, indicating a Th2 predominance in chronic HBV infection $(8,27)$. A switch to the Th1 type of response would therefore be beneficial and would promote the cellular immune mechanisms essential for viral clearance. In transgenic mice expressing $\mathrm{HBeAg}$, it has been shown that systemic application of recombinant IL-12 results in a shift of Th2-mediated responses towards predominance of Th1 cytokine profile (28). Our in vivo data indicate that IL-12 production is not impaired in patients with chronic HBV infection, but a substantial rise in IL-12 production was necessary to induce Th1 cytokine response and ultimately HBe seroconversion. The induction of endogenous IL-12 production was not a direct consequence of the IFN- $\alpha$ treatment, as it occurred only in patients with $\mathrm{HBe}$ seroconversion, but not in interferon nonresponders. In vitro data also demonstrate that IFN- $\alpha$ does not stimulate directly IL-12 priming for Th1 development (29). The observed strong association between the increase in serum levels of IL-12 and HBe seroconversion provides a rationale for the therapeutic use of IL-12 in patients with chronic hepatitis B. Thus, the present findings in patients Cell. 76:241-251.

6. Trinchieri, G. 1995. Interleukin-12: a proinflammatory cytokine with immunoregulatory functions that bridge innate resistance and antigen-specific adaptive immunity. Annu. Rev. Immunol. 13:251-276.

7. Maruyama, T., S. Iino, K. Koike, K. Yasuda, and D.R. Milich. 1993. Serology of acute exacerbation in chronic hepatitis B virus infection. Gastroenterology. 105:1141-1151.

8. Maruyama, T., A. McLachlan, S. Iino, K. Koike, K. Kurokawa, and D.R. Milich. 1993. The serology of chronic hepatitis B infection revisited. J. Clin. Invest. 91:2586-2595.

9. Kobayashi, M., L. Fitz, M. Ryan, R.M. Hewick, S.C. Clark, S. Chan, R. Loudon, F. Sherman, B. Perussia, and G. Trinchieri. 1989. Identification and purification of natural killer cell stimulatory factor (NKSF), a cytokine with multiple biologic effects on human lymphocytes. J. Exp. Med. 170:827-845.

10. Gately, M.K., A.G. Wolitzky, P.M. Quinn, and R. Chizzonite. 1992. Regulation of human cytolytic lymphocyte responses by interleukin-12. Cell. Immunol. 143:127-142.

11. Gazzinelli, R.T., M. Wysocka, S. Hayashi, E.Y. Denkers, S. Hieny, P. Caspar, G. Trinchieri, and A. Sher. 1994. Parasite-induced IL-12 stimulates early IFN-gamma synthesis and resistance during acute infection with Toxoplasma gondii. J. Immunol. 153:2533-2543.

12. Zhang, M., M.K. Gately, E. Wang, J. Gong, S.F. Wolf, S. Lu, R.L. Modlin, and P.F. Barnes. 1994. Interleukin 12 at the site of disease in tuberculosis. $J$. Clin. Invest. 93:1733-1739.

13. Clerici, M., D.R. Lucey, J.A. Berzofsky, L.A. Pinto, T.A. Wynn, S.P. Blatt, M.J. Dolan, C.W. Hendrix, S.F. Wolf, and G.M. Shearer. 1993. Restoration of HIV-specific cell-mediated immune responses by interleukin-12 in vitro. Science (Wash. DC). 262:1721-1724.

14. Desmet, V.J., M. Gerber, J.H., Hoofnagle, M. Manns, and P.J. Scheuer. 1994. Classification of chronic hepatitis: diagnosis, grading and staging. Hepa-

15. Rossol, S., R. Voth, H.P. Laubenstein, W.E.G. Müller, H.C. Schröder, K.H. Meyer zum Büschenfelde, and G. Hess. 1989. Interferon production in patients infected with HIV-1. J. Infect. Dis. 159:815-821.

16. Chisari, F.V. 1995. Hepatitis B virus transgenic mice: insights into the virus and the disease. Hepatology. 22:1316-1325.

17. Ando, K., L.G. Guidotti, S. Wirth, T. Ishikawa, G. Missale, T. Moriyama, R.D. Schreiber, H.J. Schlicht, S.N. Huang, and F.V. Chisari. 1994. Class I-restricted cytotoxic T lymphocytes are directly cytopathic for their target cells tology. 19:1513-1520. 
in vivo. J. Immunol. 152:3245-3253.

18. Gilles, P.N., G. Fey, and F.V. Chisari. 1992. Tumor necrosis factor alpha negatively regulates hepatitis $\mathrm{B}$ virus gene expression in transgenic mice. $J$. $\mathrm{Vi}$ rol. $66: 3955-3960$.

19. Guilhot, S., L.G. Guidotti, and F.V. Chisari. 1993. Interleukin-2 downregulates hepatitis $\mathrm{B}$ virus gene expression in transgenic mice by a posttranscriptional mechanism. J. Virol. 67:7444-7449.

20. Guidotti, L.G., S. Guilhot, and F.V. Chisari. 1994. Interleukin-2 and interferon alpha/beta downregulate hepatitis B virus gene expression in vivo by tumour necrosis factor dependent and independent pathways. J. Virol. 68:12651270 .

21. Guidotti, L.G., K. Ando, M.V. Hobbs, T. Ishikawa, L. Runkel, R.D. Schreiber, and F.V. Chisari. 1994. Cytotoxic T lymphocytes inhibit hepatitis B virus gene expression by a noncytolytic mechanism in transgenic mice. Proc. Natl. Acad. Sci. USA. 91:3764-3768.

22. Guidotti, L.G., T. Ishikawa, M.V. Hobbs, B. Matzke, R. Schreiber, and F.V. Chisari. 1996. Intracellular inactivation of the hepatitis B virus by cytotoxic T lymphocytes. Immunity. 4:25-36.

23. Jilbert, A.R., T.T. Wu, J.M. England, P.M. Hall, N.Z. Carp, A.P. O'Connell, and W.S. Mason. 1992. Rapid resolution of duck hepatitis B virus infections occurs after massive hepatocellular involvement. J. Virol. 66:1377-1388.

24. Kajino, K., A.R. Jilbert, J. Saputelli, C.E. Aldrich, J. Cullen, and W.S.
Mason. 1994. Woodchuck hepatitis virus infections: very rapid recovery after a prolonged viremia and infection of virtually every hepatocyte. J. Virol. 68:57925803 .

25. Jung, M.-C., U. Spengler, W. Schraut, R. Hoffmann, R. Zachoval, J. Eisenberg, D. Eichenlaub, G. Riethmüller, G. Paumgartner, H.W.L. ZieglerHeitbrock, et al. 1991. Hepatitis B virus antigen-specific T-cell activation in patients with acute and chronic hepatitis B. J. Hepatol. 13:310-317.

26. Marinos, G., H.M. Smith, N.V. Naoumov, and R. Williams. 1994. Quantitative assessment of serum IgM anti-HBc in the natural course and during interferon treatment of chronic hepatitis B virus infection. Hepatology. 19:303-311.

27. Maruyama, T., F. Schodel, S. Iino, K. Koike, K. Yasuda, D. Peterson, and D.R. Milich. 1994. Distinguishing between acute and symptomatic chronic hepatitis B virus infection. Gastroenterology. 106:1006-1015.

28. Milich, D.R., S.F. Wolf, J.L. Hughes, and J.E. Jones. 1995. Interleukin 12 suppresses autoantibody production by reversing helper T-cell phenotype in hepatitis B e antigen transgenic mice. Proc. Natl. Acad. Sci. USA. 92:6847-6851.

29. Wenner, C.A., M.L. Guler, S.E. Macatonia, A. O'Garra, and K.M. Murphy. 1996. Roles of IFN-gamma and IFN-alpha in IL-12-induced T helper cell-1 development. J. Immunol. 156:1442-1447.

30. Bertagnolli, M.M., B.Y. Lin, D. Young, and S.H. Herrmann. 1992. IL-12 augments antigen-dependent proliferation of activated T lymphocytes. J. Immunol. 149:3778-3783. 